Int. J. Dev. Biol. 52: 903-912 (2008)

doi: $10.1387 / \mathrm{ijdb} .072397 \mathrm{ka}$

\title{
Defective calcium release during in vitro fertilization of maturing oocytes of LT/Sv mice
}

\author{
KAROLINA ARCHACKA ${ }^{1,2}$, ANNA AJDUK ${ }^{2}$, PAWEL POMORSKI ${ }^{3}$, KATARZYNA SZCZEPANSKA $^{2}$, \\ MAREK MALESZEWSKI ${ }^{2}$ and MARIA A. CIEMERYCH ${ }^{1,2, *}$ \\ ${ }^{1}$ Department of Cytology and ${ }^{2}$ Department of Embryology, Institute of Zoology, Faculty of Biology, University of Warsaw and \\ ${ }^{3}$ Department of Cell Biology, The Nencki Institute of Experimental Biology, Warsaw, Poland
}

\begin{abstract}
Oocytes of LT/Sv mice have anomalous cytoplasmic and nuclear maturation. Here, we show that in contrast to the oocytes of wild-type mice, a significant fraction of LT/Sv oocytes remains arrested at the metaphase of the first meiotic division and is unable to undergo sperminduced activation when fertilized 15 hours after the resumption of meiosis. We also show that LT/ Sv oocytes experimentally induced to resume meiosis and to reach metaphase ll are unable to undergo activation in response to sperm penetration. However, the ability for sperm-induced activation developed during prolonged in vitro culture. Both types of LT/Sv oocytes, i.e. metaphase I and those that were experimentally induced to reach metaphase II, underwent activation when they were fertilized 21 hours after germinal vesicle breakdown (GVBD). Thus, the ability of LT/Sv oocytes to become activated by sperm depends on cytoplasmic maturation rather than on nuclear maturation i.e. on the progression of meiotic division. We also show that sperm penetration induces fewer $\mathrm{Ca}^{2+}$ transients in LT/Sv oocytes than in control wild-type oocytes. In addition, we found that the levels of mRNA encoding different isoforms of protein kinase $C(\alpha, \delta$ and $\zeta)$, that are involved in meiotic maturation and signal transduction during fertilization, differed between metaphase I LT/Sv oocytes which cannot be activated by sperm, and those which are able to undergo activation after fertilization. However, no significant differences between these oocytes were found at the level of $m R N A$ encoding ${ } P_{3}$ receptors which participate in calcium release during oocyte fertilization.
\end{abstract}

KEY WORDS: $L T / S v$, meiosis, in vitro fertilization, activation, calcium oscillations

\section{Introduction}

Progression of mouse oocytes through meiotic cycle, commonly described as "meiotic maturation", involves both nuclear and cytoplasmic changes (Eppig, 1996). Nuclear maturation refers to the progression of the oocyte from prophase I arrest to metaphase II arrest and involves the breakdown of nuclear envelope, chromatin condensation and the formation of metaphase I and, after first meiotic division, metaphase II spindle (Eppig, 1996). Cytoplasmic maturation consists of a number of changes that prepare the oocyte for sperm-induced activation, i.e. enable it to remodel the sperm nucleus and to support early stages of embryonic development (Carroll et al., 1996; Eppig, 1996). These changes include an increase in the level of intracytoplasmic glutathione, which is necessary for decondensation of sperm nucleus after fertilization (Perreault et al., 1988), the increase in the number of type $I$ inositol 1,4,5-trisphosphate receptors $\left(\mathrm{IP}_{3} \mathrm{R}\right.$ 1), and the increase in the level of $\mathrm{Ca}^{2+}$ stored in endoplasmic reticulum (Tombes et al., 1992; Carroll et al., 1994; Jones et al., 1995; Mehlmann et al., 1996; Parrington et al., 1998; Fissore et al., 1999; Xu et al., 2003). Some of these changes are crucial for the ability of oocyte to generate $\mathrm{Ca}^{2+}$ oscillations in response to sperm penetration that are necessary and sufficient to induce oocyte activation and progression through the first embryonic cell cycle (Ducibella et al., 2006). Mechanism responsible for oocyte activation via repetitive calcium signals involves $\mathrm{Ca}^{2+} /$ calmodulin-

Abbreviations used in this paper: CSF, cytostatic factor; GVBD, germinal vesicle breakdown; IP3R, inositol 1,4,5-trisphosphate receptor; MPF, M-phase promoting factor; PKC, protein kinase C.

*Address correspondence to: Maria A. Ciemerych. Department of Cytology, Institute of Zoology, Faculty of Biology, University of Warsaw, Miecznikowa 1, 02-096 Warsaw, Poland. Fax: 48-22-55-41-203. e-mail: ciemerych@biol.uw.edu.pl 
dependent protein kinase II (CaMKII) pathway. Activation of this kinase is crucial for the inactivation of two factors, M-phase promoting factor (MPF) and cytostatic factor (CSF; Schmidt et al., 2006). MPF is a major M-phase regulator consisting of protein kinase CDK1 and cyclin B. In metaphase II-arrested oocytes, its level is sustained due to the activity of CSF (Jones, 2004; Schmidt et al., 2006) whose key component, endogenous meiotic inhibitor 2 (Emi2), prevents the degradation of cyclin B by inhibiting Anaphase Promoting Complex (APC; Madgwick et al., 2006; Shoji et al., 2006). Activation of CaMKII leads to the degradation of Emi2 and release of APC from CSF arrest, thus allowing the completion of meiotic division.

Oocytes of LT/Sv mouse strain are an example of the abnormal regulation of meiotic maturation. Many of these oocytes are unable to complete first meiotic division and become arrested at metaphase I (MI) stage (Kaufman and Howlett, 1986; O'Neill and Kaufman, 1987; Maleszewski and Yanagimachi, 1995; Ciemerych and Kubiak, 1998). Importantly, Ml-arrested oocytes localized within the ovary can undergo spontaneous parthenogenetic activation. Formation of parthenogenetic embryos, which develop chaotically may eventually result in the ovarian teratomas or teratocarcinomas (Stevens and Varnum, 1974; Eppig et al., 1977; Artzt et al., 1987). Ovulated LT/Sv metaphase I oocytes can undergo spontaneous activation and develop into diploid parthenogenetic embryos that are able to reach the blastocyst stage and implant within the uterus (Eppig, 1978). Several research groups reported that fertilization of $\mathrm{Ml}$-arrested LT/Sv oocytes triggered their activation and resulted in the development of digynic triploid conceptuses (Kaufman and Speirs, 1987; O'Neill and Kaufman, 1987; Speirs and Kaufman, 1990; West et al., 1993). However, we demonstrated that majority of metaphase I-arrested LT/Sv oocytes were not competent to be activated by sperm and remained arrested at metaphase I (Maleszewski and Yanagimachi, 1995; Ciemerych and Kubiak, 1998). In such 'sperm-carrying' metaphase I LT/Sv oocytes spontaneous parthenogenetic activation induces formation of a male pronucleus (Ciemerych and Kubiak, 1998).

Oocytes isolated from ovaries of sexually immature wild-type mice $\left[F_{1}(C 57 B L / 6 J \times S J L)\right]$ are another example of premature termination of meiotic maturation. These oocytes begin maturation, but are unable to reach metaphase II stage and, similarly to LT/Sv oocytes, become arrested at metaphase I (Eppig et al., 1994). However, in contrast to MI-arrested LT/Sv oocytes, they can be activated by sperm or parthenogenetic agents with the same frequency as ovulated, metaphase II-arrested oocytes (Eppig et al., 1994). These data indicate that the ability of mouse oocytes to be activated depends on completion of cytoplasmic but not nuclear maturation (Eppig et al., 1994). Therefore, it is possible that inability of MI-arrested LT/Sv oocytes to be activated by sperm penetration is related to their abnormal cytoplasmic maturation.

Previously published studies described the behavior of 'in vitro cultured MI-arrested LT/Sv oocytes that were fertilized within 15 $\mathrm{h}$ after GVBD (Maleszewski and Yanagimachi, 1995; Ciemerych and Kubiak, 1998). Behavior of Ml-arrested LT/Sv oocytes that were fertilized later than $15 \mathrm{~h}$ after GVBD has never been documented. Therefore, it remained unknown whether these oocytes can acquire the cytoplasmic maturity to become activated by sperm. To answer this question we compared behavior of metaphase I LT/Sv oocytes, which were fertilized 15 and $21 \mathrm{~h}$ after GVBD. Moreover, in order to examine whether completion of nuclear maturation influence the sperm-induced activation, we compared the frequency of activation of LT/Sv oocytes arrested at metaphase I and age-matched LT/Sv oocytes that were experimentally induced to complete the first meiotic division and reached metaphase II. Since prolonged in vitro culture of metaphase IIarrested wild-type oocytes leads to the decrease in MPF activity and therefore facilitates their activation (Fissore et al., 2002), we asked whether the differences in the behavior of LT/Sv oocytes studied at different time points after GVBD could be explained by the changes of MPF activity. Finally, as it is known that oocyte activation requires calcium-dependent degradation of cyclin $B$ (Hyslop et al., 2004), we followed the $\mathrm{Ca}^{2+}$ oscillations in agematched wild-type and LT/Sv oocytes during fertilization. We also analyzed the expression of type I inositol 1,4,5-trisphosphate receptors $\left(\mathrm{IP}_{3} \mathrm{R}-1\right)$ and $\alpha, \delta$ and $\zeta$ isoforms of protein kinase $\mathrm{C}$ (PKC) which are involved in regulation of signaling pathways crucial for the meiotic maturation and/or activation of oocytes (Halet, 2004; Lee et al., 2006).

\section{Results}

\section{Delayed maturation of in vitro cultured LT/Sv oocytes}

Ninety one percent (763/843) of LT/Sv oocytes isolated at GV stage resumed meiosis i.e. underwent GVBD during first 2 hours of in vitro culture. Only these oocytes were selected for further studies. Ten, 15 or $21 \mathrm{~h}$ after GVBD the oocytes were scored for the presence of the first polar body, a sign that the first meiotic division was completed and oocytes reached metaphase II. Control wildtype oocytes were isolated from ovarian follicles and cultured in vitrosimultaneously with LT/Sv oocytes. Ninety percent $(235 / 260)$ of wild-type oocytes underwent GVBD during the first two hours after isolation. Ten hours after GVBD 79\% (352/447) of LT/Sv oocytes were still at metaphase I while $97 \%$ (228/235) of wild-type oocytes completed first meiotic division and reached metaphase II. Fifteen and 21 hours after GVBD 50.5\% (101/200) and 42.3\% (118/ 279) of LT/Sv oocytes were arrested at MI, respectively. These results agree with previous studies showing that significant proportion of in vitro maturing LT/Sv oocytes did not complete the first meiotic division and remained arrested at metaphase I stage (Albertini and Eppig, 1995; Eppig et al., 1996; Ciemerych and Kubiak, 1998). The remaining LT/Sv oocytes either progressed to metaphase II stage or became activated parthenogenetically. Activation rate was $10.1 \%(10 / 99)$ and $16.1 \%(26 / 161)$ for oocytes

\section{TABLE 1}

\section{REACTION OF METAPHASE I-ARRESTED LT/SV OOCYTES TO FERTILIZATION 15 OR 21 H AFTER GVBD}

\begin{tabular}{|c|c|c|c|c|c|}
\hline & & \multicolumn{4}{|c|}{ Hours after GVBD at the moment of fixation } \\
\hline & & \multicolumn{2}{|c|}{21} & \multicolumn{2}{|c|}{27} \\
\hline & & $\begin{array}{c}\text { fertilized } \\
\text { oocytes }\end{array}$ & $\begin{array}{c}\text { control } \\
\text { oocytes }\end{array}$ & $\begin{array}{l}\text { fertilized } \\
\text { oocytes }\end{array}$ & $\begin{array}{l}\text { control } \\
\text { oocytes }\end{array}$ \\
\hline \multirow{3}{*}{$\begin{array}{l}\text { Oocyte stage } \\
\text { at fixation }\end{array}$} & Metaphase I & $\begin{array}{l}34 / 44 \\
(77 \%)\end{array}$ & $\begin{array}{l}27 / 31 \\
(87 \%)\end{array}$ & $\begin{array}{l}2 / 38 \\
(5 \%)\end{array}$ & $\begin{array}{l}32 / 33 \\
(97 \%)\end{array}$ \\
\hline & Metaphase II & $\begin{array}{l}4 / 44 \\
(9 \%)\end{array}$ & $\begin{array}{c}3 / 31 \\
(10 \%)\end{array}$ & $0 / 38$ & $0 / 33$ \\
\hline & Interphase & $\begin{array}{c}6 / 44 \\
(14 \%)\end{array}$ & $\begin{array}{l}1 / 31 \\
(3 \%)\end{array}$ & $\begin{array}{l}36 / 38 \\
(95 \%)\end{array}$ & $\begin{array}{l}1 / 33 \\
(3 \%)\end{array}$ \\
\hline
\end{tabular}

Oocytes were fixed 21 or $27 \mathrm{~h}$ after germinal vesicle breakdown (GVBD; $6 \mathrm{~h}$ after fertilization) 

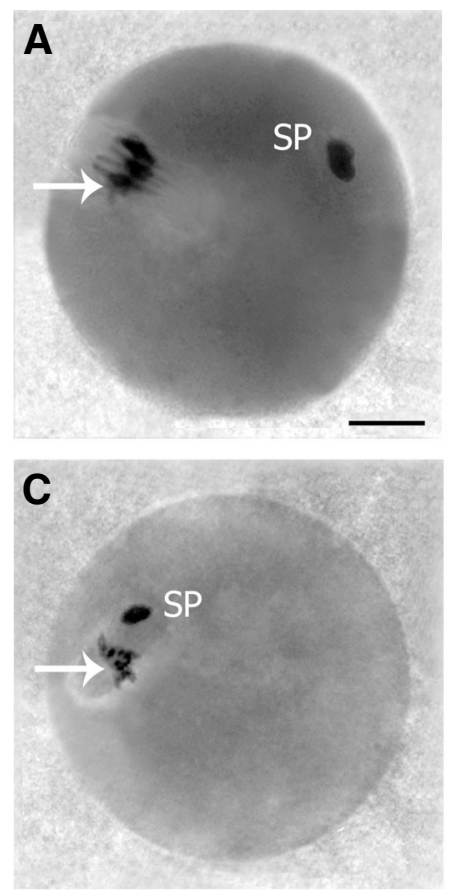
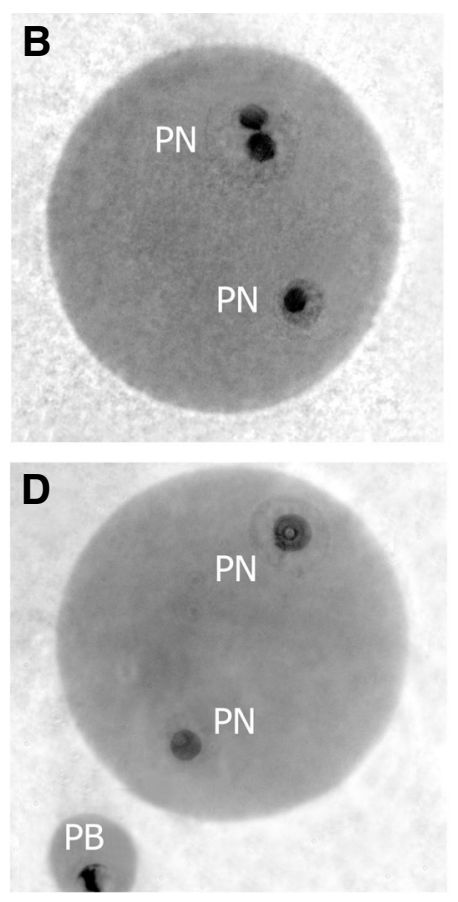

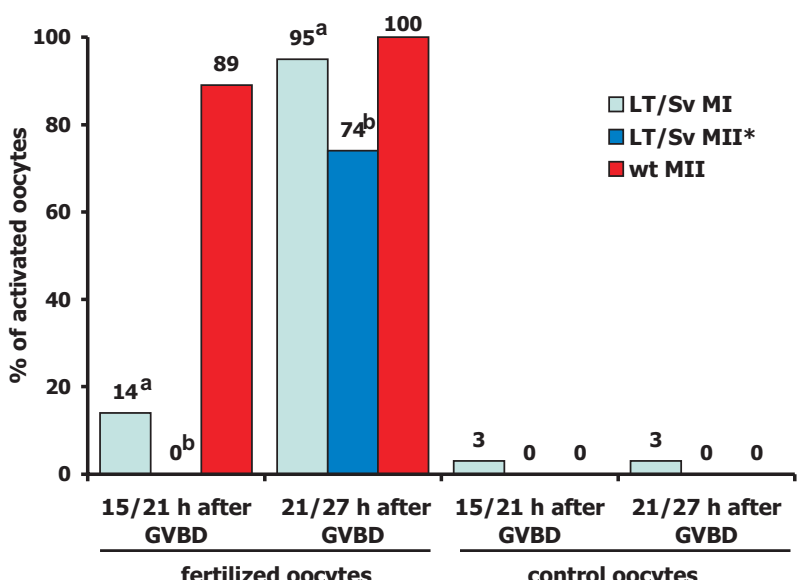

Fig. 1 (Left). Morphology of LT/Sv oocytes fertilized at metaphase I (A, B) and metaphase II* (C, D) 15 or $21 \mathrm{~h}$ after germinal vesicle breakdown (GVBD), and fixed $6 \mathrm{~h}$ after fertilization ( 21 and $27 \mathrm{~h}$ after $\mathrm{GVBD}$ ). (A) Oocyte fertilized $15 \mathrm{~h}$ and fixed $21 \mathrm{~h}$ after GVBD that remained arrested at metaphase l and contained condensed sperm chromatin. (B) Metaphase I oocyte fertilized $21 \mathrm{~h}$ and fixed $27 \mathrm{~h}$ after GVBD that completed first meiotic division and formed a one-cell embryo with two pronuclei. (C) Oocyte fertilized $15 \mathrm{~h}$ and fixed $21 \mathrm{~h}$ after GVBD that remained arrested at metaphase II* with condensed sperm chromatin localized on the metaphase spindle. (D) Metaphase II* oocyte fertilized 21 h and fixed $27 \mathrm{~h}$ after GVBD that completed second meiotic division and formed one-cell embryo with female (smaller, located close to the polar body) and male (bigger) pronucleus. Arrow indicates metaphase chromosomes. SP, condensed sperm chromatin; PN, pronucleus; PB, polar body. Bar represents $20 \mu \mathrm{m}$.

Fig. 2 (Right). Reaction of metaphase I-arrested and metaphase II*-arrested LT/Sv oocytes to fertilization. Oocytes were fertilized 15 or 21 $h$ after GVBD and fixed 21 or 27 h after GVBD. Graph represents the percentage of oocytes that become activated as a result of sperm penetration (fertilized) or spontaneously during in vitro culture (control). Columns marked with letters are significantly different (P<0.05)

scored at $15 \mathrm{~h}$ and $21 \mathrm{~h}$ after GVBD, respectively. Both metaphase II and parthenogenetically activated oocytes were excluded form further analyses. Thus, the number of metaphase l-arrested LT/Sv oocytes decreased between 10 and $21 \mathrm{~h}$ after GVBD reflecting the previously described phenomenon that, in contrast to wild-type oocytes that complete first meiotic division 8-9 hours after GVBD, in LT/Sv oocytes the completion of the first meiotic division is severely delayed (Ciemerych and Kubiak, 1998).

\section{Ability to be activated by sperm develops during prolonged in vitro culture of metaphase ILT/Sv oocytes}

Previous studies showed that MI-arrested LT/Sv oocytes which were fertilized $15 \mathrm{~h}$ after GVBD did not undergo activation in response to sperm penetration (Maleszewski and Yanagimachi, 1995; Ciemerych and Kubiak, 1998). Only LT/Sv oocytes that reached MII were able to become activated by sperm (Maleszewski and Yanagimachi, 1995). We showed previously that the progression through meiotic division is delayed in significant fraction of $L T$ / Sv oocytes (Ciemerych and Kubiak, 1998). It is possible that other cellular processes are also defective or delayed during maturation of LT/Sv oocytes. Therefore, we decided to determine whether the development of the ability to become activated by sperm is also delayed in LT/Sv oocytes.

In vitro maturing $\mathrm{MI} L \mathrm{LT} / \mathrm{Sv}$ oocytes selected 15 and $21 \mathrm{~h}$ after GVBD ( $n=75$ and $n=71$, respectively) were either inseminated (experimental group) or cultured without insemination (control group; Table 1). Oocytes that by the time of selection for the insemination reached MII or became parthenogenetically acti- vated were excluded from further analyses. Experimental and control oocytes were then cultured for additional $6 \mathrm{~h}$ and fixed 21 or $27 \mathrm{~h}$ after GVBD, respectively. Seventy seven percent of MI LT/ Sv oocytes fertilized $15 \mathrm{~h}$ after GVBD remained arrested at $\mathrm{Ml}$ at the time of fixation i.e. $21 \mathrm{~h}$ after GVBD (Fig. 1A; Table 1). Only $23 \%$ of them underwent first polar body extrusion and either reached the metaphase II stage $(9 \%)$ or become activated and formed interphase pronuclei (14\%) (Fig. 2; Table 1). In comparison, high percentage, i.e. $95 \%(P<0.05)$, of $L T / S v$ oocytes fertilized $21 \mathrm{~h}$ after GVBD underwent the first polar body extrusion and formed interphase pronuclei (Fig. 1B; Fig. 2; Table 1). The majority of control metaphase I LT/Sv oocytes that were cultured simultaneously with fertilized oocytes remained arrested at M-phase, proving that culture conditions alone did not cause the oocyte activation. When examined 21 and $27 \mathrm{~h}$ after GVBD only $3 \%$ of control oocytes, that were not inseminated, underwent spontaneous activation and contained interphase nuclei (Fig. 2, Table 1). Therefore, we concluded that the difference in frequency of activated $L T / S v$ oocytes fertilized 15 or $21 \mathrm{~h}$ after GVBD reflected the development of the ability to respond to fertilization rather than a side effect of a prolonged in vitro culture.

Cytoplasmic, not nuclear, maturation of LT/SV oocytes is required for development of their ability to be activated by spermatozoa

Hirao and Eppig (1999) showed that the incubation of MIarrested LT/Sv oocytes in the presence of an unspecific kinase inhibitor 6-DMAP induces completion of the first meiotic division. 
A

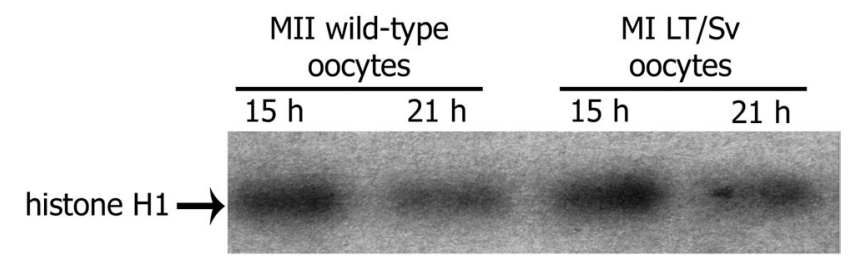

B

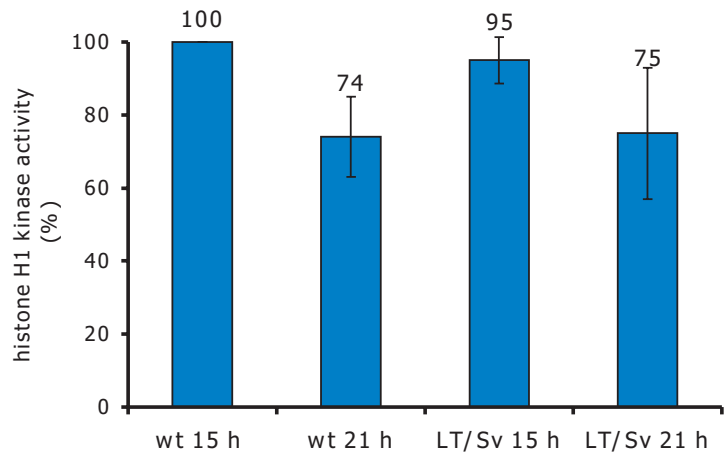

Fig. 3. Histone H1 kinase activity in metaphase I-arrested LT/Sv and metaphase II-arrested wild-type oocytes. (A) Autoradiograph of histone H1 kinase assay performed on wild-type and LT/Sv oocytes collected 15 and 21 h after germinal vesicle breakdown (GVBD). (B) The graph shows histone $\mathrm{H} 1$ kinase activity (represented by the intensity of histone H1 phosphorylation bands) in metaphase I LT/SV and metaphase I/ wild-type oocytes analyzed 15 and $21 \mathrm{~h}$ after GVBD.

We modified this experiment and before the exposure to 6-DAMP we pretreated the LT/Sv oocytes that persisted in Ml for $10 \mathrm{~h}$ after GVBD with a brief ( $5 \mathrm{~min}$ ) incubation in calcium ionophore A23187, an agent inducing $\mathrm{Ca}^{2+}$ release (see Material and Methods). Among these oocytes 53\% (186/352) completed first meiotic division and reached metaphase II stage (hereinafter called metaphase $\mathrm{II}^{\star}$, MII ${ }^{\star}$ ), i.e. extruded the first polar body but did not form interphase nucleus within 90 min of culture. These oocytes were cultured for another 3 or $9 \mathrm{~h}$ after completion of the first meiotic division, i.e. for total $15 \mathrm{~h}(\mathrm{n}=84)$ or $21 \mathrm{~h}(\mathrm{n}=62)$ after GVBD respectively. Thus, $\mathrm{MII}^{*}$ oocytes were cultured for the same period after GVBD as MI-arrested LT/Sv oocytes described in previous paragraph. Subsequently, these oocytes were either fertilized or cultured without any manipulations, and then fixed after additional 6 hours of culture i.e. 21 or $27 \mathrm{~h}$ after GVBD, respectively. Control, age-matched wild-type MII-arrested oocytes were fertilized and fixed at the same time points as LT/Sv oocytes. All of the wild-type oocytes fertilized $21 \mathrm{~h}$ after GVBD $(n=21)$ and $88.8 \%(24 / 27)$ of oocytes fertilized $15 \mathrm{~h}$ after GVBD became activated (Fig. 2). None of MII* LT/Sv oocytes $(n=49)$ that were fertilized $15 \mathrm{~h}$ and fixed 21 $h$ after GVBD underwent activation in response to a sperm penetration i.e. neither extruded the second polar body nor formed pronuclei (Fig. 1C; Fig. 2). In contrast, 74\% (31/42; P < 0.05) of MII* LT/ Sv oocytes fertilized $21 \mathrm{~h}$ and fixed $27 \mathrm{~h}$ after GVBD became activated (Fig. 1D; Fig. 2). None of control MII* LT/Sv oocytes ( $n=35$ and $n=20$, fixed 21 and $27 \mathrm{~h}$ after GVBD, respectively) that were not subjected to in vitro fertilization underwent spontaneous activation (Fig. 2), indicating that the activation of fertilized oocytes was triggered solely by a sperm penetration.

Thus, LT/Sv oocytes which were experimentally induced to reach $\mathrm{MII}^{*}$ acquired the ability to be activated by sperm penetration at the same time after resumption of meiosis (between 15 and 21 $\mathrm{h}$ after GVBD) as MI-arrested LT/Sv oocytes. Therefore, we concluded that the ability of LT/Sv oocytes to become activated by sperm depends on status of their cytoplasmic maturation rather than on the progression of meiotic division.

\section{Decrease in MPF activity accompanies the development of the ability of MI-arrested LT/SV oocytes to undergo sperm-in- duced activation}

Metaphase II arrest of oocytes is maintained by CSF that prevents cyclin B degradation and inactivation of MPF (Jones,
2004; Schmidt et al., 2006). Fissore et al. (2002) showed that the MPF activity decreases during prolonged in vitro culture of mouse oocytes leading to the increased incidence of spontaneous activation or susceptibility to induced activation. However, Hampl and Eppig (1995) showed that the rise in MPF activity accompanied metaphase I arrest of oocytes of sexually immature wild-type mice and was also observed in metaphase I LT/Sv oocytes cultured for $14 \mathrm{~h}$ after GVBD. It is possible that the increased susceptibility of metaphase I- arrested LT/Sv oocytes, cultured for prolonged time after GVBD, for sperm-induced or parthenogenetic activation is also caused by the decrease in the MPF activity. Thus, we decided to determine whether the change in the MPF activity parallels the increase in frequency of sperm-induced activation of LT/SV oocytes fertilized $21 \mathrm{~h}$ after GVBD.

Histone $\mathrm{H} 1$ kinase activity (the biochemical indicator of MPF activity) was assessed in Ml-arrested LT/Sv oocytes collected 15 and $21 \mathrm{~h}$ after GVBD. Since wild-type oocytes rarely arrest at MI, the MPF activity detected in wild-type MII oocytes collected either 15 or $21 \mathrm{~h}$ after GVBD were used as a standard for the activity assayed in MI LT/Sv oocytes (Fig. 3; see Material and Methods). We did not detect any significant differences in activity of kinase of histone $\mathrm{H} 1$ between Ml-arrested LT/Sv oocytes collected 15 after GVBD and the age-matched wild-type MIl oocytes (Fig. 3B; $P>0.05)$. Similarly, there was no difference in histone $\mathrm{H} 1$ kinase activity between MI LT/Sv and MII wild-type oocytes assayed 21 $h$ after GVBD (Fig. 3B; $P>0.05$ ). We noticed the slight decline of histone $\mathrm{H} 1$ kinase activity in both MI LT/Sv and MII wild-type oocytes collected $21 \mathrm{~h}$ after GVBD as compared to activity assayed in oocytes collected $15 \mathrm{~h}$ after GVBD, but the difference was not statistically significant (Fig. $3 \mathrm{~A}, \mathrm{~B} ; \mathrm{P}>0.05$ ). Therefore, we cannot exclude that the decrease in the MPF activity observed in MI LT/Sv oocytes $21 \mathrm{~h}$ after GVBD may facilitate their activation after fertilization, however, this does not seem to be a crucial factor in sperm-induced activation of these oocytes.

\section{Impaired $\mathrm{Ca}^{2+}$ oscillations in fertilized metaphase I $L T / S v$ oocytes}

Since the activation of oocytes arrested either at metaphase I or metaphase II requires calcium-dependent degradation of cyclin B, a regulatory subunit of MPF (Hyslop et al., 2004), we decided to study the pattern of $\mathrm{Ca}^{2+}$ oscillations during in vitrofertilization. $\mathrm{Ca}^{2+}$ response of $\mathrm{LT} / \mathrm{Sv}$ oocytes fertilized at $\mathrm{Ml}$ stage was com- 
pared to MII wild-type oocytes that generate multiple $\mathrm{Ca}^{2+}$ oscillations after sperm penetration (Cuthbertson and Cobbold, 1985; Kline and Kline, 1992). Both types of oocytes were fertilized either 15 or $21 \mathrm{~h}$ after GVBD. As expected, 91.6\% (11/12) of MII wildtype oocytes fertilized $15 \mathrm{~h}$ and $100 \%$ (9/9) of MII wild-type oocytes fertilized $21 \mathrm{~h}$ after GVBD generated 3 to $8 \mathrm{Ca}^{2+}$ transients within 90 min after sperm penetration (Fig. 4 A,B). Subsequently, these oocytes become activated. In contrast, during the same period of time only $9.5 \%(2 / 19 ; \mathrm{P}<0.05)$ of MI LT/Sv oocytes fertilized $15 \mathrm{~h}$ after GVBD had more than two $\mathrm{Ca}^{2+}$ transients. The majority of these oocytes $(90.5 \% ; 17 / 19)$ generated only one or two $\mathrm{Ca}^{2+}$ transients (Fig. 4C) and remained arrested at $\mathrm{MI}$. Similarly, one or two $\mathrm{Ca}^{2+}$ transients occurred in $78.5 \%(11 / 14)$ of MI LT/Sv oocytes inseminated $21 \mathrm{~h}$ after GVBD (Fig. 4D). More than two $\mathrm{Ca}^{2+}$ transients occurred only in $21.5 \%(3 / 14)$ of such oocytes, which was significantly less $(P<0.05)$ than in agematched wild-type oocytes. Majority of oocytes with two or more $\mathrm{Ca}^{2+}$ transients become activated. Thus, we concluded that the generation of $\mathrm{Ca}^{2+}$ oscillations is impaired in LT/Sv oocytes fertilized at metaphase I stage.

Moreover, we observed similar impaired pattern of calcium transients in LT/Sv oocytes that spontaneously completed the first meiotic division, reached metaphase II stage and then were fertilized at 15 or $21 \mathrm{~h}$ after GVBD. The majority of these oocytes generated only one or two $\mathrm{Ca}^{2+}$ transients when fertilized 15 or 21 h after GVBD $(61.5 \%, 8 / 13$ and $70 \%, 7 / 10$, respectively; Fig. 4 E,F). Only $38.5 \%(5 / 13)$ of MII LT/Sv oocytes fertilized $15 \mathrm{~h}$ after GVBD and $30 \%(3 / 10)$ of oocytes fertilized $21 \mathrm{~h}$ after GVBD had

A
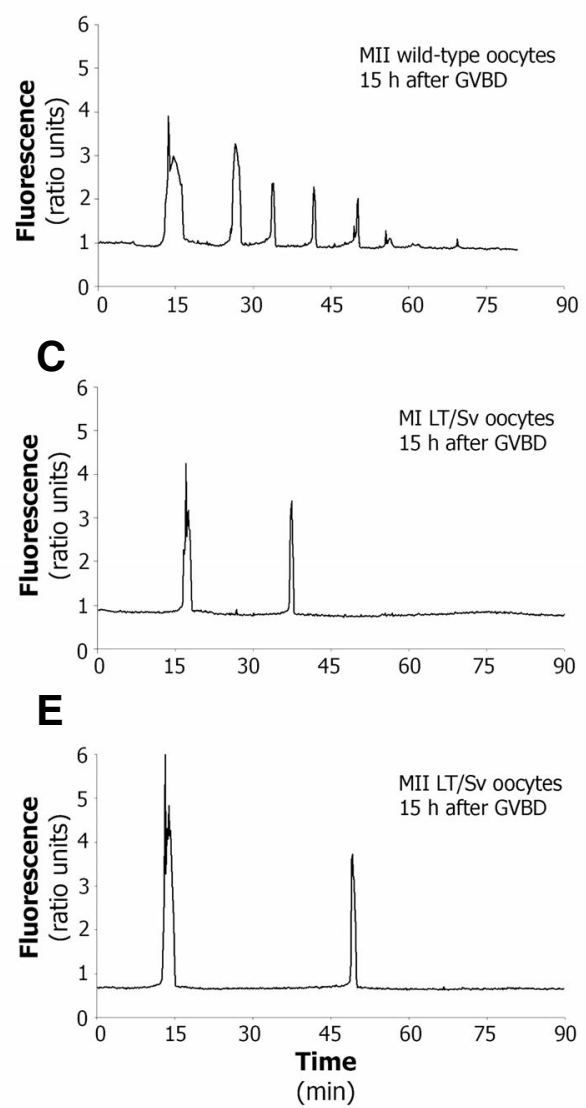

B

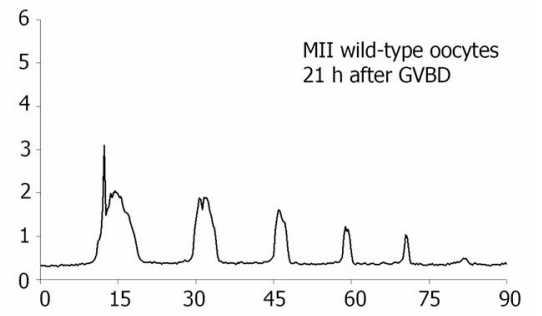

D
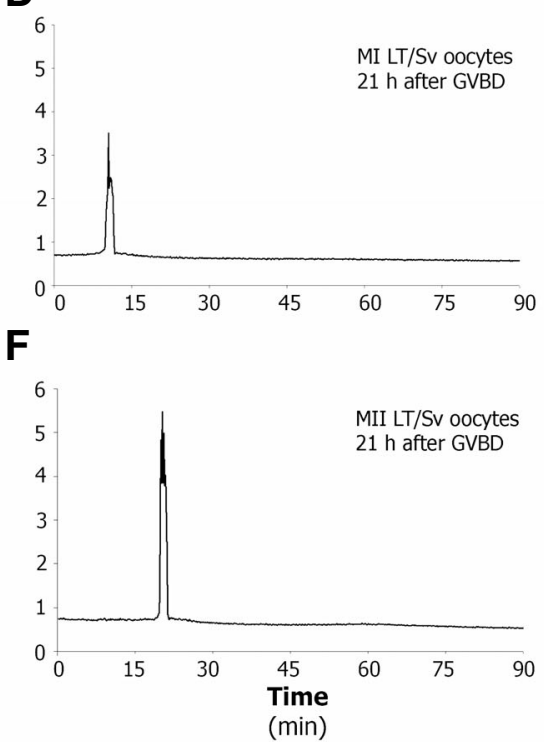

more than two $\mathrm{Ca}^{2+}$ transients, and this number was significantly lower then in age-matched wild-type oocytes (compare Fig. 4 A,B; $P<0.05)$. Since metaphase II oocytes, similarly to metaphase I LT/Sv oocytes fertilized $21 \mathrm{~h}$ after GVBD, became activated, we concluded that impairment in $\mathrm{Ca}^{2+}$ oscillations does not influence the ability of these oocytes to be activated by sperm. Moreover, the fact that $21 \mathrm{~h}$ after GVBD the LT/Sv oocytes are unable to generate long-lasting $\mathrm{Ca}^{2+}$ oscillations indicates that their cytoplasmic maturation is incomplete.

\section{Expression of $I P_{3} R-1, P K C \alpha, P K C \delta$ and $P K C \zeta$ in metaphase I LT/Sv oocytes}

Meiotic maturation and activation of mouse oocytes are regulated by several isoforms of protein kinase $C$ (PKC) (reviewed by Halet, 2004). $\mathrm{Ca}^{2+}$ oscillations depend on calcium release from endoplasmic reticulum that occurs after binding of inositol 1,4,5trisphosphate $\left(\mathrm{IP}_{3}\right)$ to type $1 \mathrm{IP}_{3}$ receptors $\left(\mathrm{IP}_{3} \mathrm{R}-1\right)$. Because our experiments showed that the fertilization of LT/Sv oocytes did not result in the repetitive $\mathrm{Ca}^{2+}$ oscillations we focused on the factors involved in $\mathrm{Ca}^{2+}$ signaling.

Using RT-PCR we compared the levels of mRNAs encoding $\mathrm{IP}_{3} \mathrm{R}-1$ and different PKC isoforms between MI-arrested LT/Sv oocytes and age-matched, MII-arrested wild-type oocytes collected at $15 \mathrm{~h}$ or $21 \mathrm{~h}$ after GVBD (Fig. $5 \mathrm{~A}, \mathrm{~B}$ ). Since it is known that the translation of given mRNA correlates with its polyadenylation status, only polyadenylated forms of mRNA were isolated from oocytes (Piccioni et al., 2005; Cui and Kim, 2007). The levels of mRNA detected in MI LT/Sv oocytes were calculated as a percentage of mRNA level (denoted arbitrally as $100 \%$ ) in age-matched MII wild-type oocytes. In each of three experiments we obtained similar results, which suggests that the differences in the expression of analyzed genes did not result from the errors in experimental procedure (see Supplementary Material, Table S1).

Analysis of the level of $I P_{3} R-1$ mRNA revealed no significant differences between $L T / S v$ oocytes analyzed 15 and $21 \mathrm{~h}$ after GVBD (P > $0.05)$ and was similar to that of age-matched wild-type oocytes (134\% and $99 \%$ of wild-type levels, respectively; $\mathrm{P}>0.05$ ) (Fig. 5A). In contrast, the level of mRNAs encoding PKC $\alpha$ and PKC $\delta$ detected in MI LT/Sv oocytes collected 15 $\mathrm{h}$ after GVBD was higher than in age-matched

Fig. 4. $\mathrm{Ca}^{2+}$ oscillations in metaphase l-arrested LT/Sv and metaphase II-arrested wild-type oocytes after fertilization. Measurements of $\mathrm{Ca}^{2+}$ oscillations in metaphase I LT/SV and metaphase /I wild-type oocytes fertilized 15 or $21 \mathrm{~h}$ after GVBD. Oscillations were measured within 90 min after fertilization. (A) Metaphase // wild-type oocyte fertilized $15 \mathrm{~h}$ after GVBD; (B) metaphase II wild-type oocyte fertilized $21 \mathrm{~h}$ after GVBD; (C) metaphase I LT/SV oocyte fertilized $15 \mathrm{~h}$ after GVBD; (D) metaphase I $L T / S$ voocyte fertilized 21 h after GVBD; (E) metaphase /l LT/SV oocyte fertilized $15 \mathrm{~h}$ after GVBD; (F) metaphase II LT/SV oocyte fertilized 21 h after GVBD. $\mathrm{Ca}^{2+}$ levels are presented as the ratio of fura 2-AM fluorescence at 340 and $380 \mathrm{~nm}$. 


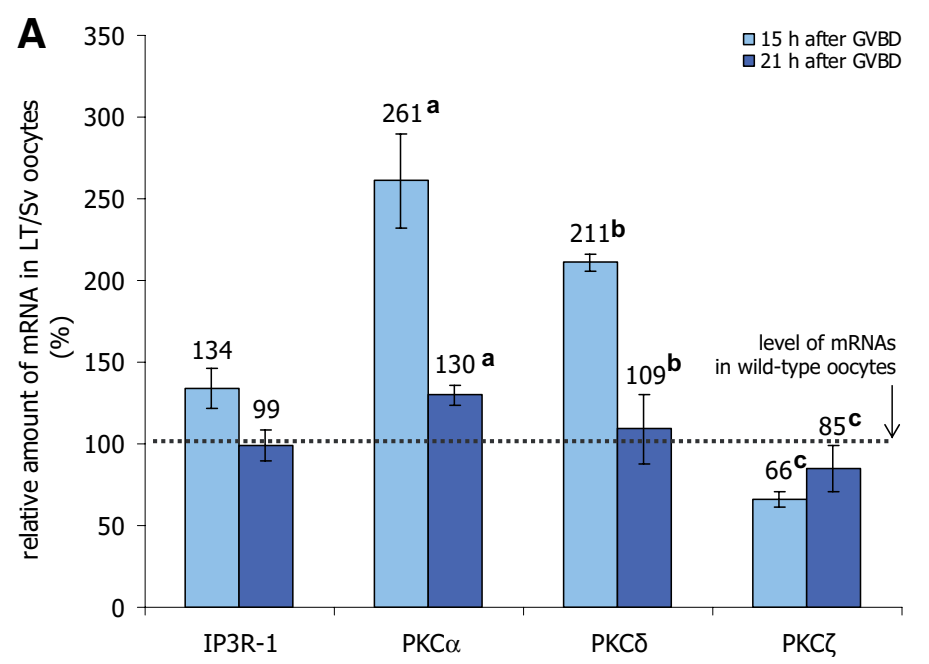

MII wild-type oocytes (261\% and $211 \%$ of wild-type levels, respectively; $\mathrm{P}<0.05$; Fig. 5A). However, there was no significant difference in the level of these mRNAs between MI LT/Sv and MII wild-type oocytes analyzed $21 \mathrm{~h}$ after GVBD (130\% and $109 \%$ of wild-type levels; $P>0.05$; Fig. 5A). The level of mRNA encoding PKC $\zeta$ analyzed $15 \mathrm{~h}$ after GVBD was lower in metaphase I LT/SV oocytes than in age-matched metaphase II wild-type oocytes ( $P$ $<0.05$; Fig. 5A). However, the level of PKC $\zeta$ mRNA was significantly higher in LT/Sv oocytes collected $21 \mathrm{~h}$ in comparison to these collected $15 \mathrm{~h}$ after GVBD (85\% and 66\% respectively; $\mathrm{P}<$ 0.05 ; Fig. $5 \mathrm{~A}$ ) and was similar to that observed in age-matched metaphase II wild-type oocytes $(P>0.05)$. Our results indicate that the level of PKC $\alpha, P K C \delta$ and PKC $\zeta$ mRNAs differ between LT/Sv and wild-type oocytes collected $15 \mathrm{~h}$ after GVBD (Fig. 5 $A, B)$, but the level of these mRNAs becomes similar $21 \mathrm{~h}$ after GVBD (Fig. 5A).

\section{Discussion}

\section{Ability of LT/Sv oocytes to be activated by sperm develops gradually during prolonged in vitro culture}

Significant fraction of maturing LT/Sv oocytes arrests at metaphase I stage (Eppig, 1978; Kaufman and Howlett, 1986). Previously we have shown that fertilization of these oocytes does not result in their activation (Ciemerych and Kubiak, 1998). Here we showed that metaphase I arrested LT/SV oocytes gradually (in a time period between 15 and $21 \mathrm{~h}$ after GVBD) develop the ability to be activated by sperm. Moreover, LT/Sv oocytes that were induced to complete the first meiotic division and reached metaphase II stage (MII*) acquired the ability to be activated by sperm at the same time point after GVBD as metaphase Iarrested oocytes. Thus, the development of this ability in LT/Sv oocytes depends on cytoplasmic rather than nuclear maturation. These results agree with previous reports on delayed maturation of oocytes of KE strain of mice. KE oocytes are characterized by prolonged metaphase I stage (Polanski, 1986; Polanski, 1995), and complete the first meiotic division a few hours later than oocytes of wild-type mice. Moreover, oocytes that remain arrested at $\mathrm{Ml}$ for $20 \mathrm{~h}$ after GVBD can be activated by sperm similarly to MII-arrested oocytes, which suggests that their cytoplasmic maturation was normal (Polanski, 1995). Oocytes iso-

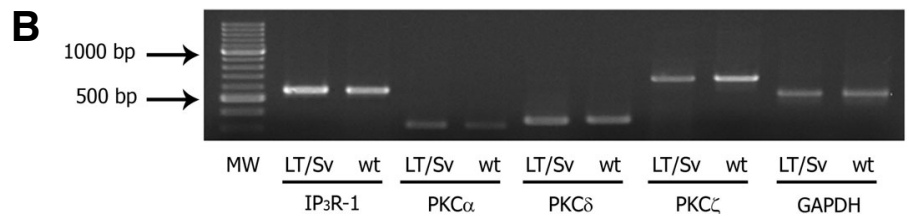

Fig. 5. mRNA level of $I P_{3} R-1, P K C \alpha, P K C \delta$ and $P K C \zeta$ in metaphase I LT/Sv and metaphase II wild-type (wt) oocytes analyzed 15 and $21 \mathrm{~h}$ after germinal vesicle breakdown (GVBD). (A) Ml-arrested $L T / S V$ and MII-arrested wild-type oocytes were analyzed 15 and $21 \mathrm{~h}$ after GVBD. The graph shows relative level of mRNA in LT/SV oocytes in comparison to the mRNA level (100\%; dotted line) in wild-type oocytes. The mRNA levels in all samples were standarized against $m R N A$ level of housekeeping gene (GAPDH). Error bars depict SEM (standard error of mean). Columns marked with letters are significantly different $(P<0.05)$. (B) Representative gel of $L T / S v$ and wild-type oocytes analyzed 15 h after GVBD. Intensity of bands reflects mRNA level in analyzed groups of oocytes.

lated from small antral follicles of sexually immature wild-type [ $F_{1}$ (C57BL/6J x SJL)] females also become frequently arrested at MI. Such oocytes can be activated by sperm with the same frequency as oocytes that progressed in nuclear maturation and reached metaphase II stage (Eppig et al., 1994). Both MI and MII-arrested wild-type oocytes do not differ in the pattern of protein synthesis, indicating that premature metaphase I arrest does not affect the cytoplasmic maturation (Eppig et al., 1994; McConnell et al., 1995). Our preliminary observations suggest that at least during initial stages of meiotic maturation i.e. until the time when wildtype oocytes become ready to complete the first meiotic division (8-9 $\mathrm{h}$ after GVBD), both wild-type and LT/Sv oocytes have similar general pattern of protein synthesis. However, we cannot exclude possibility that the subtle differences in certain proteins level are responsible for different reaction of wild-type and LT/Sv oocytes to fertilization. These differences may involve proteins functioning in the control of calcium release mechanism.

\section{MI-arrested LT/Sv oocytes are defective in the generation of sperm-induced $\mathrm{Ca}^{2+}$ oscillations}

Fusion of an oocyte and a spermatozoon triggers oscillations of intracellular calcium level (Cuthbertson and Cobbold, 1985). The increase in the intracellular $\mathrm{Ca}^{2+}$ is necessary for the activation of several signaling pathways leading to inactivation of CSF and MPF and inducing progression to the embryonic cell cycles (Ducibella et al., 2006). Our study showed that the majority of fertilized MI and MII-arrested LT/Sv oocytes generated only one or two calcium transients in contrast to MII wild-type oocytes that usually generated repetitive $\mathrm{Ca}^{2+}$ spikes in response to sperm penetration (Lee et al., 2006). The pattern of $\mathrm{Ca}^{2+}$ oscillations observed in fertilized LT/Sv oocytes resembles that which occurred in wild-type oocytes fertilized at the GV stage or during in vitro maturation (2-3 $\mathrm{h}$ after release from the ovarian follicles). Such oocytes generate fewer $\mathrm{Ca}^{2+}$ transients than oocytes fertilized in metaphase II stage (Jones et al., 1995; Cheung et al., 2000). Although the ability to be activated by sperm developed gradually in LT/Sv oocytes during metaphase I arrest, fertilization at 15 or $21 \mathrm{~h}$ after GVBD led to the same impaired pattern of $\mathrm{Ca}^{2+}$ oscillations. Moreover, even MII LT/Sv oocytes that spontaneously completed the first meiotic division failed to generate longlasting multiple $\mathrm{Ca}^{2+}$ transients. Thus, we confirmed that multiple 
calcium transients are not prerequisite for the oocyte activation. As it was previously documented MII-arrested mouse oocytes can be activated by parthenogenetic stimuli such as ethanol that induce only one $\mathrm{Ca}^{2+}$ transient (reviewed in Swann and Ozil, 1994). Such parthenogenetic embryos, despite the lack of the $\mathrm{Ca}^{2+}$ oscillations, successfully undergo preimplantation and early stages of postimplantation development (Swann and Ozil, 1994; Liu et al., 2002; Rogers et al., 2006). However, abnormally low number of $\mathrm{Ca}^{2+}$ transients observed by us in LT/Sv oocytes suggests that the signaling pathways operating at the time of fertilization may be anomalous in these oocytes and hinder their sperm-induced activation. It is known that these pathways involve the release of $\mathrm{Ca}^{2+}$ from endoplasmic reticulum. This process is mediated by inositol 1,4,5 - triphosphate $\left(\mathrm{IP}_{3}\right)$ - a product of enzymatic cleavage of phosphatidylinositol 4,5 - biphosphate $\left(\mathrm{PIP}_{2}\right)$ by sperm-specific phospholipase $\zeta(\mathrm{PLC} \zeta$ ) (Saunders et al., 2002; Swann et al., 2004). Pattern of $\mathrm{Ca}^{2+}$ oscillations generated after fertilization depends on the increase in the amount of type IIP ${ }_{3}$ receptors $\left(I P_{3} R-1\right)$ during oocyte maturation (Mehlmann et al., 1996; Parrington et al., 1998; Fissore et al., 1999; Xu et al., 2003). Xu et al. (2003) showed that the inhibition of $I P_{3} R-1$ accumulation in wild type oocytes led to the decrease in the number of $\mathrm{Ca}^{2+}$ transients. We showed the same trend for LT/SV oocytes. However, in our study we did not detect any significant differences in the level of mRNA encoding $\mathrm{IP}_{3} \mathrm{R}-1$ between MII wild-type and age-matched MI LT/Sv oocytes, which suggests that in oocytes of LT/Sv mice this part of the calcium-dependent signal transduction pathway remains normal.

\section{Development of the ability of $L T / S v$ oocytes to be activated by sperm might depend on function of PKCs}

Functional meiotic apparatus is crucial for the oocyte activation after fertilization (Winston et al., 1995). The stability of the meiotic spindle in maturing mouse oocytes is regulated by $\mathrm{PKC} \zeta$, the only PKC isoform localized at the microtubules of metaphase II spindle (Page Baluch et al., 2004). Inhibition of PKC $\zeta$ activity leads to misalignment of chromosomes and disruption of metaphase II spindle (Page Baluch et al., 2004). The role of PKC $\zeta$ in the regulation of metaphase I spindle assembly has not been examined yet, so it cannot be excluded that this isoform might be responsible for the integrity of metaphase I spindle not only in wildtype but also in LT/Sv oocytes. We showed that the level of PKC $\zeta$ mRNA is lower in Ml-arrested LT/Sv oocytes analyzed $15 \mathrm{~h}$ after GVBD as compared with age-matched MII wild-type oocytes. Several reports suggest that $\mathrm{PKC} \zeta$ can influence spindle stability by affecting the MAP kinase pathway (Schonwasser et al., 1998) that participates in the establishment of the M-phase array of microtubules during meiotic maturation (Verlhac et al., 1996; Lefebvre et al., 2002; Terret et al., 2003). It has been reported previously that the MI spindle is unstable in aging LT/Sv oocytes (Albertini and Eppig, 1995; Ciemerych and Kubiak, 1998). Thus, it is possible that the decrease in the level of PKC $\zeta$ observed in LT/ Sv oocytes $15 \mathrm{~h}$ after GVBD may influence function of their metaphase I spindle and consequently restrict their ability for sperm-induced activation.

Another isoform of $\mathrm{PKC}-\mathrm{PKC} \delta$ - was also found to be enriched at the metaphase II spindle in mouse oocytes, however, in contrast

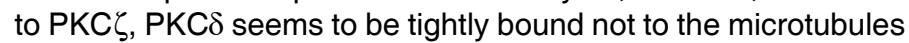
but to the chromosomes (Viveiros et al., 2001; Viveiros etal., 2003;
Page Baluch et al., 2004). PKC $\delta$ become associated with microtubules during the first meiotic division (Viveiros et al., 2001; Viveiros et al., 2003). Localization of PKC $\delta$ to metaphase I spindle in both wild-type and LTXBO oocytes (which have similar defects like LT/ Sv oocytes), prompted Viveiros and co-workers to hypothesize that PKC $\delta$ is a major PKC isoform involved in regulation of $\mathrm{MI} / \mathrm{MII}$ transition which functions by delaying the entry of oocytes into anaphase I (Viveiros et al., 2001; Viveiros et al., 2004). Consistent with this hypothesis, treatment of MI-arrested LTXBO oocytes with the PKCs inhibitor reduced MPF activity and promoted their progression to metaphase II stage (Viveiros et al., 2001). Our studies show that the level of PKC $\delta$ mRNA was 2.5 times higher in LT/Sv oocytes than in wild-type oocytes analyzed $15 \mathrm{~h}$ after GVBD. Twenty-one hours after GVBD the levels of PKC $\delta$ mRNA in LT/Sv and wild-type oocytes were similar suggesting that this class of mRNA underwent extensive deadenylation or/and degradation during the final stages of meiotic maturation. This observation seems to be consistent with previous findings that PKC activity was the highest in oocytes collected about $14 \mathrm{~h}$ after GVBD and then decreased (Viveiros et al., 2001). The abnormally high level of PKC $\delta$ mRNA found in LT/Sv oocytes arrested at metaphase I suggests that this isoform of PKC may indeed be involved in delaying the anaphase onset in LT/Sv oocytes and therefore limit their ability to be successfully activated by sperm.

We found elevated level of PKC $\alpha$ mRNA in LT/Sv oocytes analyzed $15 \mathrm{~h}$ but not $21 \mathrm{~h}$ after GVBD when compared to PKC $\alpha$ mRNA level in MIl wild-type oocytes. PKC $\alpha$ was proposed to sustain long-lasting $\mathrm{Ca}^{2+}$ oscillations in fertilized oocytes via the regulation of store-operated $\mathrm{Ca}^{2+}$-influx (Halet, 2004). However, in our study we did not notice any direct correlation between the level of PKC $\alpha$ mRNA and the number of oscillations generated in oocytes after fertilization. The number of oscillations was always higher in wild-type oocytes characterized by relatively lower level of PKC $\alpha$ mRNA. Since PKC $\alpha$ belongs to subfamily of PKC sensitive to $\mathrm{Ca}^{2+}$, our observation supports the hypothesis of Tatone and co-workers that $\mathrm{Ca}^{2+}$-independent rather than $\mathrm{Ca}^{2+}$-dependent PKCs are activated in fertilized oocytes (Tatone et al., 2003).

As mentioned above, different PKCs are believed to be involved in regulation of both meiotic maturation and response to fertilization (Halet, 2004). Our results showed significant differences in the levels of mRNAs encoding three of PKC isoforms, PKC $\alpha, \mathrm{PKC} \delta$ and $P K C \zeta$ between LT/Sv and wild-type oocytes analyzed $15 \mathrm{~h}$ but not $21 \mathrm{~h}$ after GVBD. Disparities in level of PKCs mRNAs detected in MI LT/Sv and MII wild-type oocytes $15 \mathrm{~h}$ after GVBD oocytes confirm that PKC in LT/Sv oocytes may be deregulated. Perhaps this deregulation is responsible for delaying the $\mathrm{MI} / \mathrm{MII}$ transition in these oocytes (Viveiros et al., 2001). Since level of polyadenylated mRNA reflects its translational activity (Cui and Kim, 2007), we can assume that also pattern of synthesized proteins may differ in LT/ Sv and wild-type oocytes. Differences in mRNAs levels between both groups of oocytes disappear within $21 \mathrm{~h}$ after GVBD. We also showed that $21 \mathrm{~h}$ after GVBD MPF activity is slightly lower in MIarrested LT/Sv oocytes in comparison to the oocytes $15 \mathrm{~h}$ after GVBD and this correlates with the development of the ability for sperm-induced activation in LT/Sv oocytes. However, we believe that the age-associated decrease in MPF activity is not crucial for activation of LT/Sv oocytes since majority of such metaphase Iarrested oocytes can be activated by parthenogenetic agents as early as $10 \mathrm{~h}$ after GVBD despite the presence of stable MPF 
(Ciemerych and Kubiak, 1998). This observation suggests again that the signaling cascades operating during fertilization differ in LT/Sv oocytes analyzed 15 and $21 \mathrm{~h}$ after GVBD.

\section{Genetic diversity of LT/Sv strain mice}

Our results showed that in addition to already described abnormalities the LT/Sv oocytes are also characterized by the defective calcium oscillations and delayed processes of cytoplasmic maturation. However, the molecular basis of these phenomena remains unknown. Several research groups investigated genetic linkage between different genes and meiotic abnormalities observed in LT/ Sv oocytes trying to uncover mutations responsible for this complex phenotype. West and co-workers believe that the culprit is the co-dominant autosomal gene 'poo' (primary oocyte ovulation; West et al., 1993). However, the results of other studies indicate that the phenotype of LT/Sv oocytes depends on the function of multiple genes (Eppig et al., 1996; Lee et al., 1997; Everett et al., 2004). It is possible that the incomplete penetration and variable expression of these genes lead to a great genetic heterogeneity of LT/Sv mice and make genetic mapping and understanding of LT/ Sv phenotype difficult (West et al., 1993; Lee et al., 1997; Everett et al., 2004). Similarly, at present there is no indication what genes or mutations are responsible for the LT/Sv phenotype described by us in this paper.

\section{Materials and Methods}

\section{Chemicals}

Unless otherwise stated, reagents were obtained from Sigma-Aldrich Chemical Company (Poland).

\section{Collection and culture of oocytes at germinal vesicle stage}

Two- to three-month-old LT/Sv or wild-type, i.e. $\mathrm{F}_{1}(\mathrm{C} 57 \mathrm{BI} / 10 \times \mathrm{CBA} / \mathrm{H})$ female mice were injected intraperitoneally with $10 \mathrm{IU}$ pregnant mare serum gonadotrophin (PMSG; Folligon, Intervet, Netherlands) to stimulate the development of ovarian follicles. Forty-eight to fifty-two hours later females were killed by cervical dislocation. Fully-grown oocytes arrested at prophase of the first meiotic division (germinal vesicle stage; GV) were released from ovarian follicles. Oocytes were freed from cumulus cells by pipetting and then cultured for $2 \mathrm{~h}$ in M2 medium (medium M16 buffered with HEPES; Fulton and Whittingham, 1978) containing bovine serum albumin (BSA; 4 $\mathrm{mg} / \mathrm{ml}$ ). Only oocytes that underwent germinal vesicle breakdown (GVBD) within first $2 \mathrm{~h}$ of in vitro culture were used for further experiments.

\section{Experimental induction of the first meiotic division in metaphase ILT/ Sv oocytes}

LT/Sv oocytes that failed to complete first meiotic division within $10 \mathrm{~h}$ after GVBD were placed for 5 min in solution of $\mathrm{Ca}^{2+}$ ionophore A23187 (5 $\mu \mathrm{M}$ solution in $\mathrm{M} 2$ medium) and subsequently were incubated for $30 \mathrm{~min}$ in M2 medium containing $5 \mathrm{mM}$ of unspecific kinase inhibitor 6dimetyhyloaminopurine (6-DMAP) (Hirao and Eppig, 1999). Subsequently oocytes were washed in M2 medium. Oocytes that completed the first meiotic division and reached metaphase II stage (hereinafter called metaphase $\mathrm{II}^{*}, \mathrm{MII}^{\star}$ ) within 90 min following ionophore and the 6-DMAP treatment were cultured in M2 medium before further experiments.

\section{In vitro fertilization of oocytes}

Spermatozoa from caudae epididymides of mature $\mathrm{F}_{1}(\mathrm{C} 57 \mathrm{~B} / / 10 \times \mathrm{CBA} /$ $\mathrm{H}$ ) males were suspended in $0.5 \mathrm{ml}$ of fertilization medium (Fraser and Drury, 1975) containing $4 \mathrm{mg} / \mathrm{ml}$ of BSA (Pentex, Miles, USA). Sperm concentration was approximately $2 \times 10^{7}$ spermatozoa $/ \mathrm{ml}$. Spermatozoa were incubated for $2 \mathrm{~h}$ at $37.5^{\circ} \mathrm{C}$ under $5 \% \mathrm{CO}_{2}$ in air to allow capacitation and spontaneous acrosome reaction. After incubation the sperm suspension was transferred to a tube, centrifuged ( $5 \mathrm{~min}, 1700 \mathrm{xg}$ ) and then placed back in incubator for $10 \mathrm{~min}$ to enable sperm dispersion. Spermatozoa from the upper layer of the supernatant were regarded as the most vigorous and only these were used for oocyte insemination.

LT/Sv (MI, MII*) and $\mathrm{F}_{1}(\mathrm{MII})$ oocytes were fertilized at 15 or $21 \mathrm{~h}$ after GVBD. Prior to fertilization zonae pellucidae were removed by brief ( $<1 \mathrm{~min}$ ) exposure to acidic Tyrode's solution ( $\mathrm{pH} 2.5$; Nicolson et al., 1975). Zonaefree oocytes were washed in M2 medium, transferred to $100 \mu$ droplet of fertilization medium and then $1 \mu \mathrm{l}$ of sperm suspension was added. Insemination was carried out at $37.5^{\circ} \mathrm{C}$ under $5 \% \mathrm{CO}_{2}$ in air for $30 \mathrm{~min}$. Subsequently oocytes were gently pipetted to remove loosely attached spermatozoa, cultured for $6 \mathrm{~h}$ in DMEM medium (Invitrogen, USA) supplemented with $10 \%$ of fetal bovine serum (Invitrogen, USA), 50 units $/ \mathrm{ml}$ of penicillin and $50 \mu \mathrm{g} / \mathrm{ml}$ of streptomycin, and fixed for cytological examination. Oocyte activation was assessed by the presence of the first (for MI oocytes) or second (for MII* oocytes) polar bodies and pronuclei. Each of the experimental variants was repeated three times.

\section{Measurement of intracellular $\mathrm{Ca}^{2+}$}

To monitor changes in the level of intracellular $\mathrm{Ca}^{2+}, \mathrm{LT} / \mathrm{Sv}$ (MI, MII) and $\mathrm{F}_{1}$ (MII) oocytes were incubated in $2 \mu \mathrm{M}$ solution of $\mathrm{Ca}^{2+}$-sensitive fluorescent probe, fura-2 AM (Molecular Probes, Netherlands) in M2 medium for $30 \mathrm{~min}$ at $37.5^{\circ} \mathrm{C}$ under $5 \% \mathrm{CO}_{2}$ in air (Baltz and Phillips, 1999). After loading with fura-2 AM, oocytes were washed in $\mathrm{M} 2$, released from zonae pellucidae by an exposure to acidic Tyrode's solution and transferred to heated $\left(37^{\circ} \mathrm{C}\right)$ chamber (Chance Proper LTD, Smethwick, UK) containing M2 without BSA installed on an inverted microscope stage (Diaphot, Nikon, Japan). One microliter of capacitated sperm suspension was added in a close proximity of oocytes. Sperm penetration was judged by the rise of intracellular $\mathrm{Ca}^{2+}$ within the oocyte cytoplasm. Measurements were made during 90 min after sperm penetration into the oocyte. Two excitation wavelengths of $340 \mathrm{~nm}$ and $380 \mathrm{~nm}$ were used sequentially every $10 \mathrm{~s}$ with the help of an excitation filter wheel (Lep Ludl, USA), and emission was recorded at $510 \mathrm{~nm}$ (interference filters as well as dichroic mirror from Chroma Inc., USA). Images were acquired using 10x objective and PCC (Photon Counting Camera, Retiga 1300, Q Imaging, Canada) and ratiometrically processed using AQM Advance v. 6.0 software (Kinetic Inc, UK). The experiment was repeated three times.

\section{Histone H1 kinase assay}

Histone $\mathrm{H} 1$ kinase activity (the biochemical indicator of MPF activity) was determined in in vitro cultured MII $F_{1}$ and MI LT/Sv oocytes 15 and 21 $\mathrm{h}$ after GVBD. Groups of 5 oocytes were transferred in $1 \mu \mathrm{l}$ of PBS into microcentrifuge tubes, immediately freezed and stored at $-80^{\circ} \mathrm{C}$. Next, $3 \mu \mathrm{l}$ of lysis buffer [0.16 M glicerophosphate, $40 \mathrm{mM}$ EGTA (pH 7.3), $30 \mathrm{mM}$ $\mathrm{MgCl}_{2}$, $2 \mathrm{mM}$ DTT, Complete Protease Inhibitor Cocktail (Roche, Germany), and BSA (11 mg/ml)] were added to each sample. Samples were lysed by 3 rounds of freezing and thawing. Next, $1.5 \mu$ l of reaction buffer $(0.5$ $\mathrm{mg} / \mathrm{ml}$ histone $\mathrm{H} 1,5 \mathrm{mM}$ ATP and $1.67 \mu \mathrm{Ci} / \mu \mathrm{l}$ [22P]-ATP (ICN, Prospecta, Poland) was added to each sample. Samples were incubated for $30 \mathrm{~min}$ in $30^{\circ} \mathrm{C}$. The reaction was stopped by addition of Laemmli buffer (Laemmli, 1970) Samples were boiled for $10 \mathrm{~min}$ and separated in $12 \%$ SDS-PAGE. Gels were exposed to autoradiography films (BioMax MS Film, Kodak) at $-80^{\circ} \mathrm{C}$ for 24-72 h. Intensity of autoradiography bands was measured with GelDoc apparatus and Quantity One 4.2.2 software (Biorad, Hercules, Canada). Intensity of bands reflected the activity of histone $\mathrm{H} 1$ kinase i.e. the relative amount of ${ }^{32} \mathrm{P}$ incorporated into exogenous histone $\mathrm{H} 1$. The experiment was repeated four times.

\section{$R T-P C R$}

Groups containing 25 of MII $F_{1}$ and MI LT/Sv oocytes were collected 15 and $21 \mathrm{~h}$ after GVBD and placed in $20 \mu \mathrm{l}$ of lysis buffer (DYNAL, Oslo, Norway). Samples were frozen and stored at $-80^{\circ} \mathrm{C}$. mRNA was isolated from oocytes using the Dynabeads mRNA DIRECT Micro Kit (DYNAL, 
Oslo, Norway) according to the manufacturer's protocol. For single sample $20 \mu$ of paramagnetic oligo-(dT) $)_{25}$ beads suspension was used. To bind mRNA to the oligo-(dT) ${ }_{25}$ beads the mixture was rotated for $45 \mathrm{~min}$, pelleted and then supernatant was discarded. The reverse transcription was performed in $20 \mu \mathrm{l}$ of reaction mixture containing $200 \mathrm{U}$ of Superscript II Reverse Transcriptase (Invitrogen, USA). Resulting cDNA was then divided into 5 samples (containing $4 \mu \mathrm{l}$ of CDNA) and PCR amplified (thermocycler PTC-200; MJ Research, Watertown, MA, USA) in the presence of forward and reverse primers specific for following coding se-

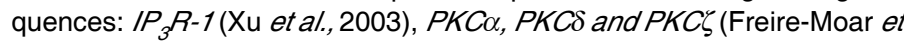
al., 1991). The levels of the PCR products were compared to the level of the PCR product of control housekeeping gene - GAPDH(Wrobel et al., 2007). The number of cycles was experimentally chosen as the lowest number needed to obtain the product that could be visualized in agarose gel. Reactions were performed under following conditions: $94^{\circ} \mathrm{C}$ for $1 \mathrm{~min}, 59^{\circ} \mathrm{C}$ for $1 \mathrm{~min}, 72^{\circ} \mathrm{C}$ for $1 \mathrm{~min} ; 45$ cycles (PKC $\alpha, \mathrm{PKC} \delta$ and $\mathrm{PKC} \zeta$ ) or 35 cycles (GAPDH and IP ${ }_{3} \mathrm{R}-1$ ); the last cycle was followed by a 10 min extension at $72^{\circ} \mathrm{C}$. The products of PCR were separated by electrophoresis in $1.5 \%$ agarose gel (Roche, Germany). RT-PCR method was considered to be the semi-quantitative. Values obtained for mRNA encoding PKC isoforms and IP3R were then compared to the values of GAPDH that were denoted as $100 \%$. Next, the mean ratio between values obtained for LT/Sv and wildtype oocytes was presented as a proportion of $100 \%$. Intensity of bands reflecting level of mRNA present in oocytes was measured densitometrically with GelDoc using software Quantity One 4.2.2 (Biorad, Hercules, Canada). Each RT-PCR analysis was repeated three times.

\section{Cytological examination}

$\mathrm{LT} / \mathrm{Sv}$ (MI, MII*, MII) and $\mathrm{F}_{1}$ (MII) oocytes were fixed with Heidenhein's fixative $6 \mathrm{~h}$ after fertilization. Whole-mount preparations were prepared and then stained with hematoxylin according to the method of Tarkowski and Wroblewska (1967).

\section{Photographic documentation and statistical analysis}

Oocytes were analyzed and photographed using Zeiss Axiovert inverted microscope equipped with a digital camera (Pixelfly, PCO). Statistical analysis of the results was performed using $\chi^{2}$ test, Fisher's exact test and t-Student test.

\section{Acknowledgements}

The Authors would like to thank dr. Jacek Kubiak and dr. Zbigniew Polanski for their comments and prof. Malgorzata Kloc for her comments and the critical reading of the manuscript. K.A. would like to thank Prof. Jerzy Moraczewski for his support during the experimental work and preparation of this manuscript.

\section{References}

ALBERTINI, D.F. and EPPIG, J.J. (1995). Unusual cytoskeletal and chromatin configurations in mouse oocytes that are atypical in meiotic progression. Dev Genet 16: 13-9.

ARTZT, K., CALO, C., PINHEIRO, E.N., DIMEO-TALENTO, A. and TYSON, F.L. (1987). Ovarian teratocarcinomas in LT/Sv mice carrying t-mutations. Dev Genet 8: 1-9.

BALTZ, J.M. and PHILLIPS, K.P. (1999). Intracellular ion measurements in single eggs and embryos using ion-sensitive fluorophores. In $A$ comparative methods approach to the study of oocytes and embryos, (ed. RICHTER, J. D.). Oxford University Press, Oxford, pp.39-82.

CARROLL, J., JONES, K.T. and WHITTINGHAM, D.G. (1996). Ca2+ release and the development of $\mathrm{Ca} 2+$ release mechanisms during oocyte maturation: $\mathrm{A}$ prelude to fertilization. Rev Reprod 1: 137-43.

CARROLL, J., SWANN, K., WHITTINGHAM, D. and WHITAKER, M. (1994). Spatiotemporal dynamics of intracellular [Ca2+]i oscillations during the growth and meiotic maturation of mouse oocytes. Development 120: 3507-17.

CHEUNG, A., SWANN, K. and CARROLL, J. (2000). The ability to generate normal
$\mathrm{Ca}(2+)$ transients in response to spermatozoa develops during the final stages of oocyte growth and maturation. Hum Reprod 15: 1389-95.

CIEMERYCH, M.A. and KUBIAK, J.Z. (1998). Cytostatic activity develops during meiosis i in oocytes of LT/Sv mice. Dev Bio/200: 198-211.

CUI, X.S. and KIM, N.H. (2007). Maternally derived transcripts: Identification and characterization during oocyte maturation and early cleavage. Reprod Fertil Dev 19: 25-34.

CUTHBERTSON, K.S. and COBBOLD, P.H. (1985). Phorbol ester and sperm activate mouse oocytes by inducing sustained oscillations in cell $\mathrm{Ca} 2+$. Nature 316: $541-2$

DUCIBELLA, T., SCHULTZ, R.M. and OZIL, J.P. (2006). Role of calcium signals in early development. Semin Cell Dev Biol17: 324-32.

EPPIG, J.J. (1978). Developmental potential of LT/Sv parthenotes derived from oocytes matured in vivo and in vitro. Dev Bio/65: 244-9.

EPPIG, J.J. (1996). Coordination of nuclear and cytoplasmic oocyte maturation in eutherian mammals. Reprod Fertil Dev 8: 485-9.

EPPIG, J.J., KOZAK, L.P., EICHER, E.M. and STEVENS, L.C. (1977). Ovarian teratomas in mice are derived from oocytes that have completed the first meiotic division. Nature 269: 517-8.

EPPIG, J.J., SCHULTZ, R.M., O'BRIEN, M. and CHESNEL, F. (1994). Relationship between the developmental programs controlling nuclear and cytoplasmic maturation of mouse oocytes. Dev Bio/164: 1-9.

EPPIG, J.J., WIGGLESWORTH, K., VARNUM, D.S. and NADEAU, J.H. (1996). Genetic regulation of traits essential for spontaneous ovarian teratocarcinogenesis in strain It/sv mice: Aberrant meiotic cell cycle, oocyte activation, and parthenogenetic development. Cancer Res 56: 5047-54.

EVERETT, C.A., AUCHINCLOSS, C.A., KAUFMAN, M.H., ABBOTT, C.M. and WEST, J.D. (2004). Genetic influences on ovulation of primary oocytes in LT/ Sv strain mice. Reproduction 128: 565-71.

FISSORE, R.A., KUROKAWA, M., KNOTT, J., ZHANG, M. and SMYTH, J. (2002). Mechanisms underlying oocyte activation and postovulatory ageing. Reproduction 124: 745-54.

FISSORE, R.A., LONGO, F.J., ANDERSON, E., PARYS, J.B. and DUCIBELLA, T. (1999). Differential distribution of inositol trisphosphate receptor isoforms in mouse oocytes. Biol Reprod60: 49-57.

FRASER, L.R. and DRURY, L.M. (1975). The relationship between sperm concentration and fertilization in vitro of mouse eggs. Biol Reprod 13: 513-8.

FREIRE-MOAR, J., CHERWINSKI, H., HWANG, F., RANSOM, J. and WEBB, D. (1991). Expression of protein kinase $C$ isoenzymes in thymocyte subpopulations and their differential regulation. $J$ Immuno/147: 405-9.

FULTON, B.P. and WHITTINGHAM, D.G. (1978). Activation of mammalian oocytes by intracellular injection of calcium. Nature 273: 149-51.

HALET, G. (2004). PKC signaling at fertilization in mammalian eggs. Biochim Biophys Acta 1742: 185-9.

HAMPL, A. and EPPIG, J.J. (1995). Analysis of the mechanism(s) of metaphase I arrest in maturing mouse oocytes. Development 121: 925-33.

HIRAO, Y. and EPPIG, J.J. (1999). Analysis of the mechanism(s) of metaphase Iarrest in strain LT mouse oocytes: Delay in the acquisition of competence to undergo the metaphase I/anaphase transition. Mol Reprod Dev 54: 311-8.

HYSLOP, L.A., NIXON, V.L., LEVASSEUR, M., CHAPMAN, F., CHIBA, K., MCDOUGALL, A., VENABLES, J.P., ELLIOTT, D.J. and JONES, K.T. (2004). $\mathrm{Ca}(2+)$-promoted cyclin $\mathrm{B} 1$ degradation in mouse oocytes requires the establishment of a metaphase arrest. Dev Bio/269: 206-19.

JONES, K.T. (2004). Turning it on and off: M-phase promoting factor during meiotic maturation and fertilization. Mol Hum Reprod 10: 1-5.

JONES, K.T., CARROLL, J. and WHITTINGHAM, D.G. (1995). Ionomycin, thapsigargin, ryanodine, and sperm induced $\mathrm{Ca} 2+$ release increase during meiotic maturation of mouse oocytes. J Biol Chem 270: 6671-7.

KAUFMAN, M.H. and HOWLETT, S.K. (1986). The ovulation and activation of primary and secondary oocytes in LT/Sv strain mice. Gamete Res 14: 255-264.

KAUFMAN, M.H. and SPEIRS, S. (1987). The postimplantation development of spontaneous digynic triploid embryos in LT/Sv strain mice. Development 101: 383-91.

KLINE, D. and KLINE, J.T. (1992). Repetitive calcium transients and the role of calcium in exocytosis and cell cycle activation in the mouse egg. Dev Bio/149: 
80-9.

LAEMMLI, U.K. (1970). Cleavage of structural proteins during the assembly of the head of bacteriophage T4. Nature 227: 680-5.

LEE, B., YOON, S.Y. and FISSORE, R.A. (2006). Regulation of fertilization-initiated [Ca2+]i oscillations in mammalian eggs: A multi-pronged approach. Semin Cell Dev Biol 17: 274-84.

LEE, G.H., BUGNI, J.M., OBATA, M., NISHIMORI, H., OGAWA, K. and DRINKWATER, N.R. (1997). Genetic dissection of susceptibility to murine ovarian teratomas that originate from parthenogenetic oocytes. CancerRes57: 590-3.

LefebVRe, C., TERRET, M.E., DJIANE, A., RASSINIER, P., MARO, B. and VERLHAC, M.H. (2002). Meiotic spindle stability depends on mapk-interacting and spindle-stabilizing protein (MISS), a new MAPK substrate. J Cel/ Bio/157: 603-13.

LIU, L., TRIMARCHI, J.R. and KEEFE, D.L. (2002). Haploidy but not parthenogenetic activation leads to increased incidence of apoptosis in mouse embryos. Biol Reprod 66: 204-10.

MADGWICK, S., HANSEN, D.V., LEVASSEUR, M., JACKSON, P.K. and JONES, K.T. (2006). Mouse emi2 is required to enter meiosis ii by reestablishing cyclin b1 during interkinesis. J Cell Bio/174: 791-801.

MALESZEWSKI, M. and YANAGIMACHI, H. (1995). Spontaneous and sperminduced activation of oocytes in LT/Sv strain mice. Dev Growth Differ37: 679685.

MCCONNELL, J.M., CAMPBELL, L. and VINCENT, C. (1995). Capacity of mouse oocytes to become activated depends on completion of cytoplasmic but not nuclear meiotic maturation. Zygote 3: 45-55.

MEHLMANN, L.M., MIKOSHIBA, K. and KLINE, D. (1996). Redistribution and increase in cortical inositol 1,4,5-trisphosphate receptors after meiotic maturation of the mouse oocyte. Dev Bio/ 180: 489-98.

NICOLSON, G.L., YANAGIMACHI, R. and YANAGIMACHI, H. (1975). Ultrastructural localization of lectin-binding sites on the zonae pellucidae and plasma membranes of mammalian eggs. J Cel/ Bio/66: 263-74.

O'NEILL, G.T. and KAUFMAN, M.H. (1987). Ovulation and fertilization of primary and secondary oocytes in LT/Sv strain mice. Gamete Res 18: 27-36.

PAGE BALUCH, D., KOENEMAN, B.A., HATCH, K.R., MCGAUGHEY, R.W. and CAPCO, D.G. (2004). PKC isotypes in post-activated and fertilized mouse eggs: Association with the meiotic spindle. Dev Bio/274: 45-55.

PARRINGTON, J., BRIND, S., DE SMEDT, H., GANGESWARAN, R., LAI, F.A., WOJCIKIEWICZ, R. and CARROLL, J. (1998). Expression of inositol 1,4,5trisphosphate receptors in mouse oocytes and early embryos: The type I isoform is upregulated in oocytes and downregulated after fertilization. Dev Biol 203: 451-61.

PERREAULT, S.D., BARBEE, R.R. and SLOTT, V.L. (1988). Importance of glutathione in the acquisition and maintenance of sperm nuclear decondensing activity in maturing hamster oocytes. Dev Bio/125: 181-6.

PICCIONI, F., ZAPPAVIGNA, V. and VERROTTI, A.C. (2005). Translational regulation during oogenesis and early development: The cap-poly(A) tail relationship. C R Bio/328: 863-81.

POLANSKI, Z. (1986). In-vivo and in-vitro maturation rate of oocytes from two strains of mice. $J$ Reprod Ferti/78: 103-9.

POLANSKI, Z. (1995). Activation of in vitro matured mouse oocytes arrested at first or second meiotic metaphase. Int J Dev Bio/39: 1015-20.

ROGERS, N.T., HALET, G., PIAO, Y., CARROLL, J., KO, M.S. and SWANN, K. (2006). The absence of a $\mathrm{Ca}(2+)$ signal during mouse egg activation can affect parthenogenetic preimplantation development, gene expression patterns, and blastocyst quality. Reproduction 132: 45-57.

SAUNDERS, C.M., LARMAN, M.G., PARRINGTON, J., COX, L.J., ROYSE, J., BLAYNEY, L.M., SWANN, K. and LAI, F.A. (2002). PLC zeta: A sperm-specific trigger of $\mathrm{Ca}(2+)$ oscillations in eggs and embryo development. Development
129: 3533-44.

SCHMIDT, A., RAUH, N.R., NIGG, E.A. and MAYER, T.U. (2006). Cytostatic factor: An activity that puts the cell cycle on hold. J Cell Sci119: 1213-8.

SCHONWASSER, D.C., MARAIS, R.M., MARSHALL, C.J. and PARKER, P.J. (1998). Activation of the mitogen-activated protein kinase/extracellular signalregulated kinase pathway by conventional, novel, and atypical protein kinase $\mathrm{C}$ isotypes. Mol Cel/ Bio/18: 790-8.

SHOJI, S., YOSHIDA, N., AMANAI, M., OHGISHI, M., FUKUI, T., FUJIMOTO, S., NAKANO, Y., KAJIKAWA, E. and PERRY, A.C. (2006). Mammalian Emi2 mediates cytostatic arrest and transduces the signal for meiotic exit via Cdc20. EMBO J25: 834-45.

SPEIRS, S. and KAUFMAN, M.H. (1990). Effect of maternal age on the incidence of digynic triploidy in LT/Sv strain mice: Implications for the ovulation of primary and secondary oocytes in this strain. J Exp Zoo/253: 83-7.

STEVENS, L.C. and VARNUM, D.S. (1974). The development of teratomas from parthenogenetically activated ovarian mouse eggs. Dev Bio/37: 369-80.

SWANN, K., LARMAN, M.G., SAUNDERS, C.M. and LAI, F.A. (2004). The cytosolic sperm factor that triggers $\mathrm{Ca} 2+$ oscillations and egg activation in mammals is a novel phospholipase C: PLCzeta. Reproduction 127: 431-9.

SWANN, K. and OZIL, J.P. (1994). Dynamics of the calcium signal that triggers mammalian egg activation. Int Rev Cyto/152: 183-222.

TARKOWSKI, A.K. and WROBLEWSKA, J. (1967). Development of blastomeres of mouse eggs isolated at the 4- and 8-cell stage. J Embryol Exp Morpho/18: 15580.

TATONE, C., DELLE MONACHE, S., FRANCIONE, A., GIOIA, L., BARBONI, B. and COLONNA, R. (2003). Ca2+-independent protein kinase $C$ signalling in mouse eggs during the early phases of fertilization. Int J Dev Bio/47: 327-33.

TERRET, M.E., LEFEBVRE, C., DJIANE, A., RASSINIER, P., MOREAU, J., MARO, B. and VERLHAC, M.H. (2003). DOC1R: A MAP kinase substrate that control microtubule organization of metaphase II mouse oocytes. Development 130: 5169-77.

TOMBES, R.M., SIMERLY, C., BORISY, G.G. and SCHATTEN, G. (1992). Meiosis, egg activation, and nuclear envelope breakdown are differentially reliant on $\mathrm{Ca} 2+$, whereas germinal vesicle breakdown is $\mathrm{Ca} 2+$ independent in the mouse oocyte. J Cel/ Bio/117: 799-811.

VERLHAC, M.H., KUBIAK, J.Z., WEBER, M., GERAUD, G., COLLEDGE, W.H., EVANS, M.J. and MARO, B. (1996). Mos is required for MAP kinase activation and is involved in microtubule organization during meiotic maturation in the mouse. Development 122: 815-22.

VIVEIROS, M.M., HIRAO, Y. and EPPIG, J.J. (2001). Evidence that protein kinase $\mathrm{C}$ (PKC) participates in the meiosis I to meiosis II transition in mouse oocytes. Dev Bio/235: 330-42.

VIVEIROS, M.M., O'BRIEN, M. and EPPIG, J.J. (2004). Protein kinase C activity regulates the onset of anaphase I in mouse oocytes. Biol Reprod71: 1525-32.

VIVEIROS, M.M., O'BRIEN, M., WIGGLESWORTH, K. and EPPIG, J.J. (2003). Characterization of protein kinase $\mathrm{C}$-delta in mouse oocytes throughout meiotic maturation and following egg activation. Biol Reprod69: 1494-9.

WEST, J.D., WEBB, S. and KAUFMAN, M.H. (1993). Inheritance of a meiotic abnormality that causes the ovulation of primary oocytes and the production of digynic triploid mice. Genet Res 62: 183-93.

WINSTON, N.J., MCGUINNESS, O., JOHNSON, M.H. and MARO, B. (1995). The exit of mouse oocytes from meiotic $M$-phase requires an intact spindle during intracellular calcium release. J Cell Sci108 (Pt 1): 143-51.

WROBEL, E., BRZOSKA, E. and MORACZEWSKI, J. (2007). M-cadherin and betacatenin participate in differentiation of rat satellite cells. Eur J Cel/ Bio/86: 99109.

XU, Z., WILLIAMS, C.J., KOPF, G.S. and SCHULTZ, R.M. (2003). Maturationassociated increase in IP3 receptor type 1: Role in conferring increased IP3 sensitivity and Ca2+ oscillatory behavior in mouse eggs. Dev Bio/254: 163-71. 


\section{Further Related Reading, published previously in the Int. J. Dev. Biol.}

See our recent Special Issue Developmental Biology in Polandedited by Kloc, Maleszewski and Tarkowski at: http://www.ijdb.ehu.es/web/contents.php?vol=52\&issue=2-3

See our recent Special Issue Ear Development edited by Fernando Giraldez and Bernd Fritzsch at: http://www.ijdb.ehu.es/web/contents.php?vol=51\&issue=6-7

CDK4 activity in mouse embryos expressing a single D-type cyclin Maria A. Ciemerych, Qunyan Yu, Katarzyna Szczepanska and Piotr Sicinski Int. J. Dev. Biol. (2008) 52: 299-305

From Planarians to Mammals - the many faces of regeneration Jerzy Moraczewski, Karolina Archacka, Edyta Brzoska, Maria-Anna Ciemerych, Iwona Grabowska, Katarzyna Janczyk-Ilach, Wladyslawa Streminska and Malgorzata Zimowska

Int. J. Dev. Biol. (2008) 52: 219-227

On the transition from the meiotic to mitotic cell cycle during early mouse development Jacek Z. Kubiak, Maria A. Ciemerych, Anna Hupalowska, Marta Sikora-Polaczek and Zbigniew Polanski Int. J. Dev. Biol. (2008) 52: 201-217

Mammalian and avian embryology at Warsaw University (Poland) from XIX century to the present Andrzej K. Tarkowski, Marek Maleszewski, Teresa Rogulska, Maria A. Ciemerych and Ewa Borsuk Int. J. Dev. Biol. (2008) 52: 121-134

Egg development in parthenogenetic nematodes: variations in meiosis and axis formation Vera Lahl, Bernd Sadler and Einhard Schierenberg Int. J. Dev. Biol. (2006) 50: 393-397

2P1, a novel male mouse cDNA specifically expressed during meiosis.

Sonia Hammami-Hamza, Mireille Doussau, Isabelle Allemand, Dominique Segretain, Jean-Marie Gasc and Catherine Finaz Int. J. Dev. Biol. (2003) 47: 71-76

Interphase-like chromatin configuration induced by cycloheximide in maturing pig oocytes: effects of protein phosphatase inhibitors.

J Rozinek, J Petr, R Grocholova and F Jilek

Int. J. Dev. Biol. (1996) 40: 1171-117

Activation of an $85 \mathrm{kDa}$ ribosomal $\mathrm{S} 6$ kinase during serotonin-induced oocyte maturation.

Y Durocher and P Guerrier

Int. J. Dev. Biol. (1996) 40: 557-566

Activation of in vitro matured mouse oocytes arrested at first or second meiotic metaphase.

Z Polanski

Int. J. Dev. Biol. (1995) 39: 1015-1020

4-aminopyridine acts as a weak base and a Ca2+ mobilizing agent in triggering oocyte meiosis reinitiation and activation in the Japanese clam Ruditapes philippinarum.

I Gobet, M Lippai, M Tomkowiak, Y Durocher, C Leclerc, M Moreau and P Guerrier Int. J. Dev. Biol. (1995) 39: 485-491

Thimerosal triggers meiosis reinitiation in oocytes of the Japanese clam Ruditapes philippinarum by eliciting an intracellular $\mathrm{Ca} 2+$ surge.

M Lippai, I Gobet, M Tomkowiak, Y Durocher, C Leclerc, M Moreau and P Guerrier Int. J. Dev. Biol. (1995) 39: 401-407
2006 ISI **Impact Factor $=3.577^{* *}$
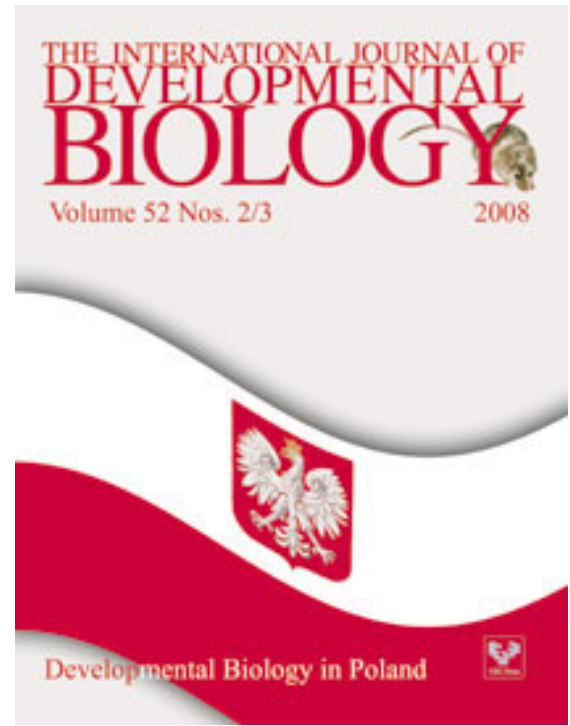